\section{EM BUSCA DA PEDAGOGIA LÚDICA: COMO BRINCAM OS PROFESSORES QUE BRINCAM EM SUAS PRÁTICAS PEDAGÓGICAS?}

\begin{abstract}
In search of playful pedagogy: how do teachers play in your pedagogical practices?
En busca de la pedagogía juguetona: cómo juegan los profesores en tus prácticas pedagógicas?
\end{abstract}

\section{Resumo}

O texto apresenta resultados de pesquisa sobre as práticas pedagógicas centradas na brincadeira, analisando excertos das narrativas de professores que se assumem, declaradamente, professores que brincam, e são identificados como tal por seus colegas e alunos. Em diálogo com diversas leituras do campo lúdico e com o reexame das próprias posições da autora sobre as relações entre jogo e educação, tais narrativas esclarecem o sentido de uma pedagogia lúdica. A intenção mais ampla do trabalho é contribuir para qualificar as ações de formação na perspectiva lúdica, acreditando que, assim, também se qualifica a escola, e, por conseguinte, pode-se melhorar a vida das pessoas, concorrendo para realizar uma autêntica transformação social por meio da promoção da inclusão escolar e da emancipação social.

Palavras-chave: formação lúdica docente; pedagogia lúdica; formação de professores; ludicidade

\begin{abstract}
This text seeks to discuss the pedagogical practices that relate to the playful. It attempts to analyze excerpts from teacher narratives known to students and colleagues as teachers who play. The objective is to clarify the meaning of a playful pedagogy, through a review of the author's own positions. More broadly, it seeks to contribute to the qualification of training actions considering a playful perspective, also qualifying the school, improving people's lives to promote school inclusion and social emancipation.
\end{abstract}

Key words: playful teacher training; playful pedagogy; teacher training; playfulness

\section{Resumen}

El texto busca discutir las prácticas pedagógicas que se relacionan con lo lúdico. Intenta analizar extractos de narraciones de maestros que los estudiantes y colegas conocen como maestros que juegan. El objetivo es aclarar el significado de una pedagogía lúdica, a través de una revisión de las propias posiciones del autor. En términos más generales, busca contribuir a la calificación de las acciones de capacitación teniendo en cuenta una perspectiva lúdica, también calificando la escuela, mejorando la vida de las personas para promover la inclusión escolar y la emancipación social.

Palabras clave: formación lúdica de docentes; pedagogía lúdica; formación de profesores; alegría

\section{AUTORA:}

\section{TÂNIA RAMOS \\ FORTUNA}

ORCID 0000-0002-3823-9792

Universidade Federal do Rio Grande do Sul

(UFRGS)

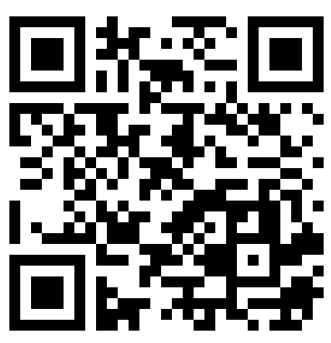

Para citar este artigo:

FORTUNA, T. R. Em busca da pedagogia lúdica: Como brincam os professores que brincam em suas práticas pedagógicas?. Revista Eletrônica Ludus Scientiae, Foz do Iguaçu, v. 03, n. 01, p. 01-19, jan./jul. 2019. 


\section{INTRODUÇÃO'}

As práticas pedagógicas ditas lúdicas difundem-se com rapidez e larga amplitude em nossa época, a ponto de constarem nos documentos legais mais recentes.

Se a Base Nacional Comum Curricular contribui em nosso país para isso no âmbito da Educação Infantil, ao identificar a brincadeira como um direito de aprendizagem e de desenvolvimento, os verbetes brincadeira e brincar, naquele documento, não se restringem à essa etapa da Educação Básica, figurando com destaque também nas recomendações aos Anos Iniciais do Ensino Fundamental. Além disso, a dimensão lúdica das práticas pedagógicas é assinalada nos Anos Finais do Ensino Fundamental, o que é muito inovador, em termos de importância atribuída à ludicidade nos documentos oficiais. Contudo, essa menção ainda está ausente no que se refere ao Ensino Médio; mas, como um dos eixos centrais de trabalho nesse nível é a apropriação pelos estudantes dos processos e das práticas investigativas, como se vê, por exemplo, no caso dos componentes curriculares Química, Biologia e da Física, e sendo esses descendentes diretos da curiosidade e da imaginação presente nas brincadeiras, o cenário também é sugestivo do ponto de vista da presença, ainda que indireta, da ludicidade no Ensino Médio.

De toda forma, já nas Diretrizes Curriculares Nacionais para a Educação Infantil a importância da brincadeira para a criança pequena era reafirmada. Também nas Diretrizes Curriculares Nacionais para o Ensino Fundamental de Nove Anos proclama-se a necessidade de recuperar o caráter lúdico do ensino e da aprendizagem nesse nível de ensino. E as Diretrizes Curriculares Nacionais para a Educação Ambiental, que abrangem todos os níveis de ensino, inclusive o Ensino Superior, preconizam que o planejamento curricular preveja a promoção de atividades lúdicas.

As próprias Diretrizes Curriculares Nacionais para a formação inicial em nível superior e para a formação continuada determinam que os cursos contemplem em seus currículos questões atinentes à ludicidade no contexto do exercício profissional nos cursos de formação inicial para os profissionais do magistério para a educação básica.

Como são essas práticas pedagógicas nas quais a brincadeira se faz presente? De que modo a ludicidade aparece na sala de aula? O que é uma aula lúdica?

Essas foram algumas das questões que me levaram a empreender a pesquisa $A$ formação lúdica docente e a universidade (FORTUNA, 2011), cujo objetivo geral era compreender o processo de formação lúdica dos professores que brincam e identificar as condições determinantes desta formação, particularmente na universidade. Entender como os professores que brincam se tornaram quem são, do ponto de vista do valor atribuído ao brincar em suas práticas pedagógicas e, mais amplamente, em sua vida, elucidando, também, as formas de realizar essas práticas, era uma das questões norteadoras do estudo.

No presente texto, excertos das narrativas de professores que se assumem, declaradamente, professores que brincam, ilustram os diferentes modos como o brincar figura em suas práticas pedagógicas. Em diálogo com diversas leituras do campo lúdico e o reexame de minhas próprias

\footnotetext{
${ }^{1}$ As ideias contidas neste trabalho têm sido apresentadas em numerosos eventos na área da Educação no Brasil, sendo parte delas já publicadas em diferentes meios. Sou grata possibilidade de expô-las e pela acolhida e disposição de discuti-las em todas essas oportunidades, o que têm contribuído para ampliar nossa compreensão sobre a Pedagogia Lúdica. Elas foram abordadas também na Palestra de Abertura "Brincar é aprender: dimensões conceituais e operacionais da abordagem lúdica do ensino” realizada no III JALEQUIM - Encontro Nacional de Jogos e Atividades Lúdicas no Ensino de Química, Física e Biologia, realizado em Foz do Iguaçu, em dezembro de 2018. Na ocasião, tais ideias foram objeto de uma escuta entusiasmada e de um instigante debate. Agradeço a oportunidade de retomá-las na forma desse texto, prolongando a reflexão desencadeada naquele inesquecível momento.
} 
posições sobre as relações entre jogo e educação, essas narrativas me conduziram ao encontro do sentido de uma pedagogia lúdica.

No limite, a intenção do presente texto é contribuir para qualificar as ações de formação na perspectiva lúdica, acreditando que, assim, também se qualifica a escola, e, por conseguinte, pode-se melhorar a vida das pessoas, concorrendo para realizar uma autêntica transformação social por meio da promoção da inclusão escolar e da emancipação social.

\section{COMO BRINCAM OS PROFESSORES QUE BRINCAM}

\section{O estudo: método e sujeitos}

A partir das histórias formativas em relação ao brincar, narradas, brincando, pelos professores participantes do estudo, foi possível compreender como se dá a brincadeira em suas aulas. Tais histórias, coletadas através da prática da ludobiografia, técnica de pesquisa que desenvolvi a partir dos trabalhos de Staccioli e seus colaboradores (STACCIOLI, 2003, 2005, 2010; ORBETTI; SAFINA; STACCIOLI, 2005; DEMETRIO, 1997; DI PIETRO, 2003) com crianças, como parte do movimento de levar a autobiografia à escola, foram obtidas mediante a proposição de atividades lúdico-expressivas. Nessas atividades, o jogo tornou-se o conteúdo a ser pesquisado nas histórias de vida dos professores que têm a brincadeira presente em sua prática pedagógica e, ao mesmo tempo, um meio para compreender como e por que, afinal, tais professores se tornaram quem eles são, isto é, professores que brincam ${ }^{2}$.

Participaram do estudo oito professores de diferentes níveis de ensino e variada formação inicial e continuada, selecionados em função da notória presença da brincadeira em suas práticas pedagógicas. Na impossibilidade de apresentá-los detalhadamente, o que extrapolaria o objetivo deste texto, descrevo-os sinteticamente através do mote que estabeleci para cada um deles, como se fora uma espécie de holograma pessoal, cuja formulação, pregnante de sentido, ao mesmo tempo em que adensa e acentua algumas de suas características, deixa entreabertas suas demais formas e possibilidades de ser: Neusa - "modo diamante de ser", Anerosa - "um lugar para brincar"; Johannes "o 'nós' que envolve"; Hétzia - "a fazedora de brinquedos"; Rosinês - "o olhar que vai além"; Jouet - "a onça que brinca"; Wanda - "a bruxa alegre e amiga contadora de histórias"; Liège - "Liebe, esforço e coragem" (nomes ou codinomes escolhidos pelos próprios professores para serem identificados na pesquisa). Com idades entre trinta e cinquenta anos, eles tinham à época da investigação entre oito e 26 anos de serviço, sendo que alguns trabalhavam ou haviam trabalhado na rede pública de ensino, na esfera municipal, estadual ou federal, enquanto outros tinham experiência no ensino privado. Composto em sua maioria por mulheres, havia apenas um professor homem no grupo de docentes investigados. Entre esses professores, havia quem tivesse experiência na Educação Infantil e no Ensino Fundamental, Médio e Superior, incluindo também a atuação na Educação Especial e na Educação Física.

Para fins de concisão e harmonia do texto, as narrativas sobre o brincar são evocadas através de paráfrases e, sempre que possível, das palavras de cada autor, preservando seu próprio modo de se expressar. Entremeando-as às minhas reflexões, pretendo trazer, da forma mais concreta e o mais inteiramente possível, os próprios sujeitos da pesquisa para dentro do texto.

\section{O amplo arco da pedagogia lúdica}

Poder-se-ia dizer que o modo de brincar desses professores configura um amplo arco, no qual, em uma das extremidades figura a construção e a utilização de jogos e na outra ponta o que poderia ser chamado de uma atitude lúdica que se estende à vida, como um todo, marcada pelo humor, pelo

\footnotetext{
${ }^{2}$ Mais esclarecimentos sobre a ludobiografia como abordagem de pesquisa em Educação, ver FORTUNA, 2012a, 2012b, 2012c).
} 
riso e pelo envolvimento com o outro e com a situação; entre uma e outra dessas extremidades estão a abordagem lúdica de situações e materiais, como textos humorísticos, música, poesia, e o uso da magia e da fantasia, inclusive e particularmente na contação de histórias. Os professores em questão deslizariam de uma extremidade a outra do arco, concentrando suas práticas num ou noutro ponto dele.

Deduz-se, portanto, que são múltiplas as camadas de sentido com que se revestem os modos de brincar dos professores. Se não fosse possível enfeixá-las, todas, sob a identidade do jogo (ou da brincadeira, já que trato como equivalente esses termos, interessada, tal como Sutton-Smith (2017), mas no que há em comum nos diferente componentes do campo lúdico, do que em sua distinção), de modo a conservar seus atributos comuns, seria apenas confusão, haja vista a máxima de Pascal: "a multiplicidade que não se reúne para a unicidade é confusão" - ao que ele acrescenta: "a unicidade que não depende da multiplicidade é tirania” (PASCAL, 2005, p. 263). Não é, contudo, o que acontece: todas essas formas, aparentemente tão díspares, não constituem um todo heteróclito, mas, sim, um conjunto muito harmônico, se bem que, igualmente, muito dinâmico.

De toda maneira, para além do recenseamento minucioso das atividades realizadas nas aulas do professor que brinca - afinal, como pondera Terr, "existem tantas formas de jogar quantos indivíduos há no mundo" (TERR, 200o, p. 215, tradução minha) - o que importa é entender a sua atitude, a prevalência do "espírito do jogo" em seu modo de agir. Como ele se apresenta na aula do professor que brinca?

\section{A atmosfera e a textura lúdica}

Para Sarlé (2006), o que está em jogo é a "atmosfera lúdica”, ou seja, aquilo que envolve aspectos tão díspares como os espaços nos quais se produz o ensino quanto o tipo de vínculo que se cria entre os alunos e o professor na sala de aula. Essa atmosfera compõe a "textura lúdica" da aula, pois ainda que existam algumas atividades chamadas jogos, o aspecto lúdico impregna as práticas da vida escolar.

E o que caracteriza a "atmosfera lúdica"? Segundo Huizinga (1993), o que define uma situação como lúdica é o fato de ela ser livre, realizar-se em uma esfera temporária da vida, com orientação própria, capaz de absorver o jogador de maneira intensa, desligada de qualquer interesse material e praticada segundo certas regras. Identificar tais características é, como diz Chapela, "seguir o rastro do jogo" (CHAPELA, 2002, p. 81).

Com efeito, nem todas as características enumeradas acima são identificáveis nas descrições dos professores sobre a sua prática pedagógica. Porém, com base naquilo que foi possível interpretar a partir de suas narrativas lúdicas, tudo indica que algumas situações são ludiformes, como diria Visalberghi (1965), isto é, tem formato lúdico, embora não possam ser inteiramente arroladas como jogo. Mas, se a ênfase no resultado (a aprendizagem de um conteúdo curricular) se sobrepuser à satisfação decorrente da realização da atividade, deslocando-se do processo para o produto, e se as ações dos jogadores já estiverem todas pré-programadas, essas atividades terão, então, se transformado em jogos didatizados. Sob esses efeitos adiaforizantes - para expressar-me como Bauman (2009), ao referir-se ao enfraquecimento e à perda de poder de alguns conceitos no mundo contemporâneo arriscam-se, até, a deixarem de ser jogo. Importa frisar que os jogos e brincadeiras didatizadas nada tem a ver com uma didática lúdica.

A propósito da didática lúdica, muito poderia ser dito, pois alguns autores, empenhados em sistematizar a abordagem lúdica na sala de aula, assim a denominam. Centrada em materiais definidos como lúdico-didáticos, a didática lúdica propõe atividades interessantes e alegres que propiciam a construção de conhecimentos e o desenvolvimento de habilidades, explica Chapela (2002). Porém, o que definirá a presença da didática lúdica em uma situação será, não o objeto em si, já que ele pode 
servir tanto como brinquedo, como material lúdico-didático, mas a intenção do adulto que o põe à disposição dos alunos e das circunstâncias que o cercam. Mesmo assim, segundo a autora, como na didática lúdica falta a liberdade, já que a atividade não é espontânea como o é no jogo, os alunos, através dela, estarão estudando e aprendendo com os materiais, mas não estarão jogando. Ainda conforme Chapela, há outra expressão da didática lúdica que compartilha com o jogo algumas características, sendo a fronteira que existe entre o jogo e o ensino mais sutil: é o caso do uso criativo de ideias e palavras. Para Chapela, trata-se de uma atividade lúdico-didática quando "é o educador quem pede ao aluno que realize os exercícios, quando é ele quem estabelece as regras a seguir, quando espera que logrem determinadas aprendizagens"; em contrapartida, trata-se de jogo quando "o desejo de atuar surge dos próprios estudantes, que não jogam para aprender - ainda que o façam - senão para sentir a emoção do risco, a incerteza da expectativa, a sensação de pertencer a um grupo ou a alegria de alcançar logros inesperados" (CHAPELA, 2002, p. 48).

A meu juízo, na aula com jogos ao professor cabe a tarefa de zelar pela brincadeira, impedindo que se transforme em jogo didatizado e, assim, se extinga sua dimensão lúdica (FORTUNA, 20oo). Por isso é tão relevante distinguir com nitidez o papel do professor em relação aos jogos: suas atitudes perante o jogo são fundamentais para que uma aula seja lúdica. Sem ser intrusivo, tampouco omisso, o professor que zela pela brincadeira na aula lúdica realiza uma intervenção aberta, baseada na provocação e no desafio; também sem corrigir ou determinar as ações dos alunos, ele as problematiza, apoiando-os em sua realização (FORTUNA, 200o). De acordo com Brougère, o professor "incita" (1999, p. 5).

Adotando outra linha de pensamento, D’Ávila (2014) define a didática lúdica como a arte de mediar com arte, sustentando que a dimensão da arte é um ingrediente indispensável ao ensino lúdico.

Exemplo disso é o que relatou Wanda a propósito de suas aulas de Português nas séries finais do ensino fundamental, nas quais costumava trabalhar com letras de música, prosa e poesia e também com a leitura dos escritos dos próprios alunos. As crônicas de Luís Fernando Veríssimo sempre fizeram parte de suas aulas, assim como a teatralização dos livros lidos na hora da leitura, durante a aula; segundo ela, mais interessantes do que as tradicionais fichas de leitura, essa prática não só melhorava consideravelmente a leitura, como levava os alunos a se apaixonarem por ela.

Em suma: a textura lúdica de uma aula não se define estritamente pela presença física de um jogo ou de um brinquedo, ou pela proposta concreta de um jogo de regras ou uma dinâmica lúdica, pois alguns desses jogos podem, no limite, "jogar contra” o brincar, descaracterizando-o.

Na pesquisa, Johannes mostrou-se inclusive crítico em relação à "palhaçada" e construção de jogos e materiais lúdicos de ensino, prática que logo associa ao predomínio do fazer sobre o teorizar. Mas admitiu que, se brincar na sala de aula for envolver os alunos por inteiro, de forma ativa e abrangente em uma atividade - não somente o raciocínio, mas, também, as emoções, transcendendo a simples exposição do conteúdo de ensino -, então, sim, ele é um professor que brinca.

Como se vê, a textura lúdica parece funcionar como uma espécie de subestrutura e de marco comum no qual se configura a situação de ensino, frequentemente é como se ela atuasse por si mesma; segundo Sarlé (2006), assim se explica porque o jogo muitas vezes aparece como um elemento impossível de ser registrado pelo professor e em certa medida torna-se invisível quando se quer precisar qual é o seu lugar no conjunto das atividades de ensino.

\section{Dar aula "como se" fosse brincadeira}

Sendo assim, o que vale não é contabilizar com exatidão o quantum de dimensão lúdica e de dimensão pedagógica estão presentes em uma situação ou atividade, mas a presença da brincadeira no modo de agir - no caso desta pesquisa, no agir do próprio professor, mas que diz respeito, também, 
ao agir dos alunos. E isso transparece com nitidez nos relatos dos professores sobre suas aulas. Nelas, é "como se" eles brincassem: parecem separados no tempo e no espaço da realidade ordinária, como se estivessem em transe; mostram-se capazes de brincar com os pensamentos, com as ideias e com a própria realidade, através do humor; embora planejem cuidadosamente suas aulas, deixam-se levar pelo improviso e pelo imprevisto, sobretudo ao instaurar um diálogo com os alunos, seja de fato, seja em pensamento; renunciam à centralização, à onisciência e ao controle abrindo espaço para o surgimento do que ainda não existe e do que não se sabe; o que inquieta e mobiliza estes professores para o ensino é o seu próprio desejo de aprender e de fazer saber. Deste modo, arrebatados, professor e aluno evadem-se temporariamente da realidade, mas somente pelo tempo suficiente de pensar, imaginar, inventar, pois o material necessário à atividade criativa é a própria realidade.

Para Neusa, mais do que forma de pensar o processo educativo, técnica ou ferramenta de trabalho, a experiência do brincar, seja em sala de aula ou fora dela, é uma filosofia de vida, um compromisso que assume consigo mesma enquanto condição existencial, enchendo sua vida de sentido.

Jouet, por seu turno, contou na pesquisa que, com seus alunos universitários, trabalhou com Freud em quadrinhos e até hora do conto já fez, apagando as luzes e utilizando uma linguagem diferente para ser agradável: ao acender as luzes, os alunos estavam focados; aí, então, ela trazia a teoria. Isso porque, segundo Jouet, é preciso ter o mistério, havendo também um jogo de sedução. Jogo do qual Jouet participa ativamente, não somente como "mestre do jogo", mas como jogadora.

O brincar dos professores, exibe-se, assim, em toda a sua profundidade e inteireza: para além de jogos em torno de conteúdos escolares ou de dinâmicas de integração, de brinquedos e sua construção, de narração de histórias e de mágicas que utilizam em suas aulas, os professores brincam porque, eles mesmos, dão aula como se brincassem. Eles brincam de brincar: denomino a isso "brincadeira de segunda potência", como se verá melhor mais adiante. Creio que, esta sim, é a ponta mais extrema daquele arco que descrevi como contendo as diferentes formas de brincar do professor que brinca.

É no "como se", em sua dimensão de não-literalidade, que está a brincadeira. Possivelmente esses professores, quando dão aula, estejam naquele estado de fluxo (flow), tal como concebido por Csikszentmihalyi (200o): uma experiência ótima caracterizada por um estado mental em que a consciência de si mesmo e o sentido ordinário de tempo desaparece, devido ao envolvimento total com a realização de algo que dá grande prazer, embora possa ter um grande custo. Não obstante as teses desse autor não sejam objeto de consenso entre os teóricos do jogo ${ }^{3}$, elas são facilmente identificáveis em situações tais como a de realização de um trabalho gratificante, no qual se experimenta as mesmas sensações extraídas do brincar infantil. Ele observou em suas pesquisas, inclusive, um envidamento extra de esforços nesses estados de fluxo, nos quais as pessoas mostram-se ainda mais comprometidas e dedicadas àquilo que fazem; elas estão tão sérias quanto uma criança que brinca - tal como Freud (1976), aliás, declarara sobre os escritores criativos. Isso porque o jogo, longe de dever ser considerado algo que diverte, no sentido de que desvia a atenção ou desvia do caminho Staccioli (2003) esclarece que a palavra divertir deriva do Latim divertere, que significa voltar a outro lugar, desviar, fugir, ir a outra parte -, ou como um assunto trivial, é um ato humano realmente sério, naquele sentido de ser real, verdadeiro e sincero, sem engano ou burla, dubiedade ou dissimulação; essa é, por sinal, a definição de seriedade que consta no dicionário da Real Academia Espanhola, como ressalta Chapela (2002, p. 87). A rigor, divertir-se com os jogos não é fugir, mas buscar um "outro lugar": "um lugar que oferece visões diversas, perspectivas e ângulos inéditos, ocasiões irrepetíveis, visões inesperadas" (STACCIOLI, 2003, p. 63, tradução minha).

3 Um de seus críticos é Sutton-Smith (2017), para quem o autor húngaro promove uma idealização do jogo e uma mescla com o trabalho que tornam o próprio conceito de jogo inespecífico e, por isso, pouco operacional. 


\section{O brincar na sala de aula e a intencionalidade pedagógica}

Outro aspecto a destacar no modo como brincam os professores investigados diz respeito à questão da intencionalidade pedagógica, tema que já foi abordado linhas acima, no contexto da reflexão a criação da atmosfera lúdica da sala de aula como sendo uma das formas de atuar do educador que brinca.

É indubitável nos relatos dos professores o compromisso com o ensino de seus alunos. O fato de desenvolverem aulas lúdicas não os afasta, minimamente sequer, desse compromisso. No entanto, observa-se que ele tem um caráter ampliado, alinhando-se ao que preconiza Charlot, quando afirma que ensinar é mais do que transmitir e fazer aprender saberes: "é, por meio de saberes, humanizar, socializar, ajudar o sujeito singular acontecer, é ser portador de uma certa parte do patrimônio humano, é preencher uma função antropológica." (CHARLOT, 2005, p. 85). Para os professores que brincam, como para esse autor, "aprender não é apenas adquirir saberes, no sentido intelectual e escolar do termo; é também apropriar-se de práticas e de formas relacionais e confrontar-se com a questão do sentido da vida, do mundo, de si mesmo. " (CHARLOT, 2005, p. 57). Sem descurar da centralidade dos processos de aprender e ensinar, a aula lúdica requer e resulta em uma nova composição dos saberes que se contrapõe à forma hegemônica, rígida e hierarquizada, que separa e opõe aprender e brincar.

Anerosa indicou como uma grande inovação em sua prática pedagógica a organização de momentos de brincadeiras em recreios mais prolongados, com brinquedos e jogos à escolha dos alunos e a participação dos professores, tentando aproximar os momentos ditos de brincar, dos momentos ditos de aprender. Ela também se dedica às brinquedotecas, o que explicita a sua preocupação em garantir oportunidades de brincar às crianças; já os jogos, as brincadeiras e a confecção de brinquedos levados por ela às praças da cidade, bem como a revitalização de praças e criação de ruas de lazer, respondem ao seu desejo de ampliar a ludicidade para a cidade.

Contudo, a intencionalidade pedagógica, nas aulas dos professores investigados, não subverte a própria brincadeira. O professor que brinca, mesmo tendo uma assumida intenção em relação à aprendizagem de seus alunos, não subordina rigidamente a brincadeira aos seus propósitos pedagógicos: como afirmei em outro lugar, ele "resigna-se a respeitar o rumo, o fim que tomará a atividade, admitindo seu componente aleatório, a dimensão de autonomia e mesmo sua improdutividade no âmbito da economia social ou pedagógica dos conteúdos", o que faz do brincar na sala de aula uma aposta (FORTUNA, 2000, p. 163).

Talvez essa seja a parte mais difícil do exercício de uma pedagogia lúdica consequente, na qual o caráter de aula não seja preterido, sobretudo quando o que esse professor deseja é a ampla promoção da aprendizagem dos seus alunos. Há que se considerar que, como bem observa Green, algo não programado não significa indesejado: no caso da criança não programada, diz ele, "ela é mais desejada que os outros, pois escapa à intenção e é o fruto de um desejo inconsciente" (1999, p. 23). Pode-se, pois, deduzir que, ao não programar com rigor os jogos utilizados em suas aulas, o professor que brinca assegura as condições propícias a que o desejo advenha.

Também no ensino superior Wanda descreveu seu trabalho com músicas, jograis, teatro, debates, jogos, leitura de histórias com as quais busca dinamizar as aulas, sempre "imaginando um jeito legal de transmitir os conteúdos".

Rosinês, por seu turno, por meio de uma das atividades ludobiográficas propostas na pesquisa, que se maravilha ao mostrar para uma criança uma coisa tão difícil para compreender e que se torna fácil quando se usa um jogo. 
Logo, a preocupação em tornar as aulas interessantes, gostosas e prazerosas não se sobrepõe à preocupação com o desenvolvimento e a aprendizagem dos alunos; ao contrário, ambas as preocupações se harmonizam. Aqui também vale recorrer ao que diz Charlot sobre o assunto: para ele, uma aula interessante é "uma aula na qual se estabelece, de forma específica, uma relação com o mundo, uma relação consigo mesmo e uma relação com o outro.” (CHARLOT, 200o, p. 73). Acrescento: é aquela aula na qual o aluno e o professor acham-se implicados, naquele estado de fluxo no qual o envolvimento é total. É, portanto, uma aula na qual se pode, de fato, estar brincando com jogos e atividades ludiformes, mas é, sobretudo, aquela aula na qual é "como se" professores e alunos brincassem. É o fato de conter uma brincadeira de segunda potência - o brincar de brincar, como denominei acima - que garante, ao mesmo tempo, brincar, ensinar e aprender.

Ainda quanto à preocupação com as aulas interessantes, ela é mais uma evidência do intenso envolvimento do professor com a tarefa de ensinar. A consideração do ponto de vista dos alunos parece ser fundamental para o professor que brinca; não se trata, todavia, de uma absolutização da perspectiva do outro e, concomitantemente, um apagamento da própria posição, de modo que o professor deixese escravizar pelo objetivo de satisfazer os alunos. Penso que o professor que brinca encontra-se naquele terceiro nível da evolução do egocentrismo à descentração, tal como descrita por Marques (2005) em seu estudo sobre a docência no ensino superior: se no primeiro nível o professor não diferencia o ponto de vista do aluno do seu próprio ponto de vista e no segundo, embora já os diferencie, não os coordena, no terceiro nível o professor, além de diferenciar, consegue coordenar os distintos pontos de vista que se constituem em sala de aula.

\section{A construção de jogos e materiais ludiformes}

Em alguns casos, a preparação de aulas interessantes pode envolver a elaboração de materiais ludiformes e a construção de jogos com e para os alunos.

Liège, por exemplo, trabalhou na criação de jogos especiais para alunos surdos em um programa de Extensão Universitária voltado à formação lúdica do educador e na Feira do Livro realizou contação de histórias com língua de sinais, nela lançando seu livro O Feijãozinho Surdo. Como explicou na pesquisa, esse livro resultou da articulação entre a teoria (as leituras sistemáticas do Mestrado), a confecção de materiais para o ensino-aprendizagem e as brincadeiras em sala de aula com seus alunos surdos.

Já Rosinês contou na pesquisa que gosta de brincar e criar coisas novas com material descartável, tendo um armário cheio de sucata para criação de materiais e outro com jogos, alguns para as crianças se divertirem com seus colegas, outros relacionados aos conteúdos trabalhados, e que nem por isso deixam de ser gostosos de trabalhar. Relatou que cultiva o olhar aguçado no material reciclado para fazer um novo jogo e que gosta de perceber o mesmo nos alunos.

Hétzia revelou nas brincadeiras realizadas nos encontros ludobiográficos que descobriu sua paixão pelas coisas ligadas às artes e aos trabalhos manuais durante o curso de Magistério, nas atividades práticas e de confecção de materiais. Essa dimensão de seu modo de ser professora se salientou tanto em sua narrativa a ponto de determinar seu mote na pesquisa: "a fazedora de brinquedos".

Intrigada com a presença marcante dessa dimensão construtiva na prática pedagógica do professor que brinca, fui em busca de possíveis explicações teóricas. Após identificá-la, inicialmente, como um vestígio da perspectiva empirista do processo de ensino-aprendizagem, assimilando a ênfase no material concreto e na experimentação à importância atribuída aos meios e às técnicas educacionais por parte de teorias psicológicas como a do condicionamento operante, tomei-a como um efeito da influência do pensamento pedagógico da Escola Nova. Para isso, considerei, sobretudo, a perspectiva da Escola Ativa e a posição de fundamentar o ato pedagógico na ação, na atividade da criança, em 
nome da tese de "aprender fazendo", da qual Dewey foi um dos principais difusores. Afinal, foram os grandes pensadores desse movimento que propalaram a importância do jogo para a educação, como Piaget, Montessori, Decroly e o próprio Dewey, cujas vozes ecoaram no Brasil nas escolas experimentais e de aplicação e nos cursos de formação de normalistas, com o reforço dos pioneiros da Educação Nova, como Lourenço Filho ${ }^{4}$. Aliás, dada a remanescência do escolanovismo no ideário das práticas pedagógicas lúdicas, elas são alvo frequente das mesmas críticas a ele destinadas: teriam um otimismo pedagógico alienado e reeditariam acrítica e ingenuamente o escolanovismo, em forma de um neotecnicismo pedagógico, transfigurado, sob uma concepção panegírica do jogo, em uma manobra diversionista em relação aos propósitos mais elevados e críticos da educação ${ }^{5}$. Mais recentemente, sob a influência dos Estudos Culturais, essas práticas têm sido criticadas pela naturalização da associação da criança ao brinquedo e acusadas de serem um instrumento de controle e regulação infantil ${ }^{6}$.

No caminho da busca de entendimento sobre a alta importância atribuída ao material concreto na prática pedagógica por alguns dos professores investigados, encontrei na definição de Maffesoli (2008) para a palavra "concreto" elementos que me ajudaram a refletir com mais profundidade sobre o assunto. Segundo o autor, concreto vem de cum-crescere, isto é, aquilo que cresce com, desenvolvendo-se de maneira global e integrando o conjunto dos elementos do dado social e natural. Para ele, o pressuposto empírico - no qual identifico a ênfase no concreto - é uma característica e uma necessidade dos tempos pós-modernos que proclama a necessidade de viver a vida como ela é, no aqui e agora. Nessa perspectiva, a empiria não se reduz ao imediatamente palpável, mas abrange, "ao mesmo tempo, o estático e o dinâmico, aquilo que é constante e o que é movente", na forma de um "enraizamento dinâmico" (MAFFESOLI, 2008, p. 114). Talvez os professores que brincam recorram com tanta frequência ao material concreto em suas aulas lúdicas porque anseiam pela integração da experiência - o sensível, a aparência, o vivido - ao conhecimento escolar.

Por fim, encontrei no pensamento de Winnicott (1975) uma interpretação a respeito7: "o objeto deve ser apresentado para, paradoxalmente, ser criado", recordam Outeiral e Moura, baseados em Winnicott (OUTEIRAL; MOURA, 2002, p. 3). A partir desse preceito winicottiano, identifiquei o envolvimento de alguns professores que brincam com a construção de materiais para as suas aulas como uma forma de estimular a criatividade de seus alunos: ao oferecer-lhes as suas criações, eles permitiriam que os próprios alunos criassem. Esta também poderia ser uma forma do professor exercer a sua própria criatividade, configurando, assim, um modo muito pessoal de continuar brincando, mesmo dando aula. Isso parece tanto mais plausível quanto mais for considerado o fato de que, para Winnicott (1975), a experiência criativa se situa naquele mesmo espaço intermediário no qual surge a capacidade de brincar. Dela deriva o viver criativo, isto é, a capacidade de transitar entre o dentro e o fora e de abandonar-se a estados não-integrados, com a confiança de que é possível uma reintegração. Mesmo que para Winnicott a criatividade não seja uma experiência exclusiva dos artistas ou dos gênios, pois tem a ver com a capacidade que cada ser humano tem de experimentar o mundo de forma original, no caso da criação literária e de jogos, os professores, convertidos em artistas, talvez busquem a construção de si próprios nas manifestações artísticas; ao mesmo tempo, se expõem à admiração dos outros, constituindo-se através desse olhar. Como asseveram Outeiral e Moura (2002), a criação artística, refletindo a busca ativa de integração inerente ao seu criador, é um espaço no qual se conciliam o ser e o fazer, o dentro e o fora, o conteúdo e a técnica.

Outra hipótese, mas na mesma linha de pensamento, é que suas construções atuem tal qual o objeto transicional que o bebê elabora e do qual descende a capacidade de brincar: constituem tanto

4 Sobre isso ver, por exemplo, História das Ideias Pedagógicas, de Gadotti (2005).

5 Exploro esse tema em minha participação em Brincar com o Outro (OLIVEIRA; BORJA SOLÉ; FORTUNA, 2010).

${ }^{6}$ Como exemplo dessa crítica, remeto à leitura de “Criança e brinquedo: feitos um para o outro?”, de Bujes (200o).

7 Devo a Gianfranco Staccioli a sugestão de interpretar a preocupação do professor que brinca com a elaboração de materiais ludiformes e jogos pedagógicos para as suas aulas através do conceito de objeto transicional, a quem mais uma vez agradeço. 
uma ponte entre elas e seus alunos ou seus leitores, quanto um espaço que a separa deles, propiciando sua emergência como não-eu. Recordando o jogo do rabisco, ele é uma maneira de entrar em contato com a criança: quem sabe os brinquedos e jogos construídos com seus alunos não sejam a maneira do professor que brinca entrar em duplo contato - com o seu aluno-criança e com a sua própria criança interior?

Seja como for, os jogos e os materiais ludiformes, como textos humorísticos e jogos pedagógicos, e, da mesma forma, as músicas e a poesia, têm o potencial de criar a situação de afordância descrita por Brougére (2004) em relação a alguns brinquedos; ela seria capaz de desencadear a brincadeira na aula lúdica e, ao fazê-lo, propiciar também a aprendizagem. Como sustenta sabiamente Terr, "o jogo se alimenta do jogo" (2000, p. 216).

\section{Brincar de brincar: a brincadeira de segunda potência}

Creio que há, ainda, uma terceira forma de ser professor que brinca: é o brincar de brincar. Já afirmei, linhas atrás, que a isso denomino brincadeira de segunda potência: o professor, ao dar aula "como se" estivesse brincando, está brincando, pois o "como se" é um dos traços definidores da brincadeira; além disso, ele brinca com jogos e atividades ludiformes, tendo em vista a aprendizagem e o desenvolvimento de seus alunos. Ele brinca, pois, duas vezes. Fink (2008) demonstra ter reparado nessa possibilidade de o jogo ser jogado, quando afirma que o homem joga também com o próprio jogar. Creio que é o brincar de brincar, e não somente brincar, que o mantém na posição de professor, isto é, deliberada e intencionalmente engajado na tarefa de ensinar, portanto, pedagogicamente comprometido. Se, simplesmente, brincasse com seus alunos - e isso verdadeiramente acontece em alguns momentos e em determinadas atividades, ainda que, a rigor, a brincadeira jamais seja simples -, o professor que brinca, nessa condição, momentaneamente colocaria em segundo plano seu papel de professor, em benefício de ser um companheiro de jogo. Não há problema em que isso aconteça pontualmente; afinal, não exercemos um único papel, o tempo todo. Enquanto estamos no lugar de professores, podemos, eventualmente, ter despertado em nós o papel de mãe, filho, amante, advogado, médico, companheiro de jogo, aluno, colega, etc., conforme o caso. Brincar diante do outro é uma eficiente forma de mobilizá-lo para a brincadeira, convidando-o a brincar também, brincando junto. Mas, ao brincar de brincar, o professor brinca com a própria brincadeira. Ele, ao mesmo tempo em que brinca, tem uma consciência lúdica, isto é, uma consciência que, sem ser inata, constrói-se ao longo da formação profissional e existencial do professor e expressa, através de atitudes e de conhecimento, a valorização do brincar na vida, identificando-o como afirmação da vida e através da qual se compromete com o brincar; essa consciência, que se expressa através de uma posição ativa, lúcida e crítica em relação ao brincar e à educação, envolve saber olhar, escutar, compreender, relacionar conhecimentos, dar sentido à experiência lúdica, enfim (FORTUNA, 2005).

A redundância presente na fórmula "brincar de brincar" assegura que o professor, a um só tempo, brinque e ensine, conciliando esses termos postos tradicionalmente em relação de oposição. O comportamento do professor que brinca de brincar constitui uma unidade complexa, na qual esses termos, se individualizados, não têm o mesmo sentido que possuem quando combinados.

Hétzia, por exemplo, descreveu seu modo de brincar como professora desde a entrada dos alunos em aula, até o término das atividades: brinca com seus alunos na "rodinha", de jogo da forca, mímicas, brincadeiras cantadas e dinâmicas de integração, e, no momento da brincadeira livre, participa das brincadeiras dos alunos no balanço e no trepa-trepa, brincando também de massinha com eles. Nesses momentos ela tem clareza de que brinca, e, ao mesmo tempo, está atenta às suas responsabilidades pedagógicas, o que confere uma característica especial a esse tipo de brincadeira, distinta daquelas que faz quando se diverte, fora do contexto da escola.

Do ponto de vista da teoria dos tipos lógicos de aprendizagem de Bateson (1998a), brincar de brincar se inscreve no tipo II de aprendizagem, caracterizada pelo comportamento de aprender a 
aprender, mas acredito que ela pode, inclusive, evoluir em direção ao tipo III, tornando-se mais complexa à medida que se torna mais abrangente e reflexiva; nesse caso, o professor brincaria de brincar de brincar - como pode suceder com os formadores de professores nessa área.

Recordo, aqui, o depoimento de Jouet, em relação à aula com hora do conto, luzes apagadas e linguagem diferente, criando um clima de mistério, e, depois, a entrada da teoria em cena: ela de fato brinca, mas, também, brinca de brincar.

De acordo com Staccioli (2003), o jogo que joga com o jogo configura um paradoxo lúdico, no qual se está dentro do jogo (é um ser no jogo, que joga de acordo com as suas regras) e fora dele (no sentido de ter consciência do jogo, examinando criticamente essas regras). Seria possível estar dentro e fora? Isso ainda seria um jogo? Segundo o autor, sob a perspectiva do paradoxo, as duas coisas não se excluem, mas oscilam de uma a outra - o que, aliás, acrescento eu, é próprio do jogo, isto é, esse trânsito constante entre o dentro e o fora, o real e o imaginário, a regra e a liberdade.

\section{A aula como festa}

A meu ver, a aula do professor que brinca - a aula lúdica -, quaisquer que sejam as formas empregadas, parece uma festa.

É o que sugere o depoimento de Wanda na pesquisa, para quem as palavras "aula" e "aluno" remetem à aventura, travessura e ensinar-aprender como gostosura.

É no pensamento de Gadamer que recolho inspiração para pensar a aula lúdica como festa. E, como para ele, a festa é "a essência da comunicação recuperada de todos com todos" (GADAMER, 1985, p. 23), proponho que a aula lúdica, uma vez tomada como festa, seja definida como a arte do encontro.

Na qualidade de um acontecimento coletivo, por meio do qual um amplo repertório simbólico é compartilhado, a festa possui um forte poder agregador, reforçado pela intenção de festejar que une os participantes (CALLEJO, 1999). Expectativa e tensão percorrem-na de ponta a ponta, configurandoa como uma experiência-limite somente suportável devido ao regime de exceção que a caracteriza regime esse que a torna ainda mais esperada. Como modo, lugar e ocasião para a experiência tanto do novo quanto da tradição, do sagrado e do profano, do íntimo e do público, do solene e do prosaico, da sobriedade e da irreverência, a festa representa a condensação de uma experiência social ímpar.

Igualmente Fink relaciona o jogo à festa e à ideia de encontro, notando que a comunidade arcaica em festa "abraça" os espectadores, os iniciados e os adeptos daquela espécie de jogo cultual que nela se realiza, da mesma forma que a comunidade de jogo "abraça" as formas e as figuras do estar junto e torna possível a representação de uma existência inteira: "ela é a realidade da vida humana em todos os seus aspectos”, resume o filósofo (FINK, 2008, p. 33, tradução minha). Aliás, para esse autor, o jogo é fundador de comunidade, dado que, originariamente, ele é a maior potência coercitiva, embora seja diferente da comunidade entre os mortos e os vivos, do ordenamento usual de poder e, ainda, da família elementar; ele é uma possibilidade fundamental de existência social, uma forma íntima da comunidade humana; mesmo o jogo solitário mais obstinado realiza-se em um horizonte de comunhão com os outros, diz Fink (2008). Porém, isso não quer dizer que a comunidade de jogo somente se defina enquanto tal por consistir de um conjunto de pessoas reais, já que basta pelo menos um jogador real e efetivo para que se trate de um jogo real, explica o autor. Aliás, "ao mundo do jogo pertencem sempre coisas reais", nota Fink, ainda que "algumas tenham o caráter de aparência ôntica", enquanto "outras se revistam de uma aparência subjetiva, que provém da alma humana." (FINK, 20o8, p. 38, tradução minha).

Estudando os mitos e o homem religioso, Eliade percebe que "participar religiosamente de uma festa implica a saída da duração temporal ordinária e a reintegração no tempo mítico reatualizado pela 
própria festa." (2010, p. 64). O tempo da festa é um outro tempo, um tempo de sonho, o tempo primordial; por meio dela, afirma Eliade, o homem religioso torna-se contemporâneo dos deuses. Os rituais inscrevem-se nela como modo de tornar presente "algum acontecimento sagrado que teve lugar $a b$ origine"; assim, os próprios participantes da festa tornam-se contemporâneos do acontecimento mítico, encontrando a dimensão sagrada da existência (ELIADE, 2010, p. 79). Nada leva a crer, porém, que se trate de recusa do mundo real e evasão no sonho e no imaginário. De acordo com Eliade, o desejo de restabelecer o tempo da origem através da festa não representa apenas encontrar os deuses, mas o próprio mundo "tal como era in illo tempore", o que a torna, "ao mesmo tempo, sede do sagrado e nostalgia do Ser.” (2010, p. 84).

Além do mais, o regime de exceção que a festa instaura é também responsável pelos excessos que ela pode comportar. Como diz Caillois, "a festa constitui um excesso permitido através do qual o indivíduo se encontra dramatizado e se torna o herói: o rito realiza o mito e permite a sua vivência." (CAILLOIS, 2017, p. 24).

No contexto da veemente defesa que Maffesoli (2005) faz do paradigma dionisíaco, cujo retorno é por ele identificado como uma reação à unidimensionalidade econômico-tecnocrática da contemporaneidade, esse aspecto da festa assinalado por Caillois é recordado: a festa evoca o caos original, que permanece como um elemento da ordem existente, sendo, por isso, sempre excessiva, lembrando, no extremo, um crime, um ato de desobediência, uma revolta, a morte de um deus ou de um personagem célebre. "Como momento cristalizador da força societal", diz o autor, a festa "contém uma forte carga de excesso, de morte, mas, assim, ela administra a morte, acomoda-se à sua presença constante e chega mesmo a brincar astuciosamente com ela." (2005, p. 83). Para Maffesoli, o orgiasmo - conceito-mestre de sua obra e que equivale a uma das estruturas essenciais da sociabilidade, pela qual o valor dos sentimentos se afirma no jogo societal - é uma das formas festivas que, integrando a morte, participa do vasto processo da fecundidade. Mas esse aspecto exaltado da festa é necessário, até mesmo vital, na perspectiva do autor, pois a explosão das paixões na festa dá ao conflito de valores que lhe é subjacente uma forma aceitável; perigoso, a seu ver, é recusar esse procedimento, pois equivale a expor-se ao possível retorno do recalcado - essa seria a sombra de Dioniso. Daí que, conforme Maffesoli, "é na festa, bem mais do que em estruturas abstratas de troca ou circulação, que se opera a passagem da 'natureza' à 'cultura', sob mediação de Dioniso (2005, p. 158).

Não obstante opor-se à interpretação de que o paradigma dionisíaco estaria em plena vigência na contemporaneidade, vendo "no frenesi do consumo-mundo", isto sim, um ideal apolíneo, Lipovetsky (2007) também identifica na festa a tarefa de voltar a dar vida, simbolicamente, depois do caos e da morte, ao corpo coletivo.

Tentando compreender a sociedade do hiperconsumo que, a seu juízo, é a que estamos vivendo, ele a compara a uma "minifesta": o ato de consumo visa, na busca do novo, redinamizar o aqui agora (LIPOVETSKY, 2007, p. 70). Porém, para o autor, a sociedade do hiperconsumo, diferentemente dos cultos dionisíacos do passado, que praticavam, através do êxtase e do frenesi transgressivos, a inclusão coletiva, é caracterizada pela crescente individualização dos modos de vida. Assim, para Lipovestsky, a festa e o universo do lazer contemporâneo são marcados pela "privatização dos prazeres, da individualização e da comercialização do tempo livre"; "a lógica que triunfa é a do tempo individualista do lazer-consumo." (LIPOVETSKY, 2007, p. 211-2). Não se trata mais de celebrar uma divindade, um ser, um acontecimento a que a coletividade atribui uma importância particular ou de perpetuar a lembrança e de conservar vivas as tradições: "as festas do presente têm como característica animar o presente dos indivíduos, transformando-o em tempo lúdico e recreativo." (LIPOVETSKY, p. 2007, p. 253). Viveríamos, segundo ele, a revitalização do Homo festivus, com o exercício do direito ao prazer, ao não-sério, à explosão de alegria.

E agora? A qual dessas festas a aula lúdica se compara? A festa que exalta o coletivo e as origens, ou aquela que enaltece o presente e o consumo? 
Para Neusa, ao relatar seu modo de ser professora que brinca - que, segundo enfatiza, é apenas uma faceta do modo de ser sujeito, pessoa que brinca - diz questionar-se constantemente: "de quais sujeitos eu desejo ser cúmplice em seus processos formativos? Que tipo de pessoas estou ajudando a construir?". Segundo ela, sua ação pedagógica é caracterizada por investir em atividades que colaborem na construção do autoconceito e da autoestima dos alunos. Neusa demonstra, assim, uma forte preocupação com o aluno e o desejo de entrar em contato profundo com ele.

De forma semelhante Rosinês se pronuncia, afirmando que gosta de garimpar nos alunos o que cada um tem de melhor e sempre procurar formas diferentes de proporcionar encantamento nos alunos com um jogo ou uma brincadeira.

A propósito de produzir encantamento na sala de aula, Neusa citou o fato de ter feito o curso de Extensão Universitária de "Formação de Brinquedista"; sem ele, acha que continuaria sendo aquela professora que não brincava, insatisfeita com o que fazia e da forma que fazia, não conseguindo transmitir aos seus alunos o encantamento pela vida e a possibilidade de fazê-los descobrir os caminhos para atingir a realização pessoal e profissional.

Mesmo que a festa contemporânea, no entender de Lipovetsky, esteja a serviço da procura da felicidade dos indivíduos, o certo é que tanto em uma quanto na outra, vive-se o "o prazer de sentir o júbilo coletivo, de viver um estado de efervescência compartilhada, de sentir-se próximo dos outros." (LIPOVETSKY, 2007, p. 255). Não concordo com o autor, porém, quando ele diz que a festa contemporânea é a festa ajuizada, em oposição à festa dionisíaca que excitava todos os sentidos. Creio que persiste, ainda que de forma variável, a dimensão de excesso, que se expressa em seu lado transgressor, de exceção.

Dito isso, penso que, tal qual na festa, na aula lúdica realizam-se atividades que só ali podem acontecer. Essas atividades - o jogo, ritual por excelência, o riso, o estado de fluxo - transportam para um outro tempo, que é o tempo da imaginação e do "como se fosse", mas também para o "mundo das ideias", de modo que esse passa a ser o mundo que interessa. É como se o mundo lá fora se tornasse, ele, e não o mundo da aula lúdica, um outro mundo - tal qual Calvino descreve a experiência do espectador de cinema, que ouve os ruídos da rua como "o chamado daquele outro mundo que era o mundo." (CALVINO, 200o, p. 46). Inclusive, creio que é esse regime de exceção o que permite que adultos, raramente capazes de jogar espontaneamente, como observa Fink (2008), assim o façam na aula lúdica. Justamente, o encantamento a que se referem as professoras que participaram da pesquisa.

Para Gadamer (2007), a festa só existe na medida em que é celebrada. Assistir a uma festa é participar verdadeiramente dela - como o faz o theoros da metafísica grega, aquele espectador que participa do ato festivo, esquecido de seus próprios objetivos e que conduz ao sentido de theoria: "a partir daquilo que o sujeito está olhando" (2007, p. 182). Sendo assim, se a aula lúdica é uma festa, isso quer dizer que dela se participa ativamente, estando o professor e os alunos nela plenamente implicados. Penso, contudo, que a aula lúdica entendida como festa não diz respeito a qualquer encontro, senão aquele encontro do ato de ensinar com o ato de aprender, da mesma forma que nela se encontram os sujeitos e os objetos desse processo. É vivenciada coletivamente como celebração da vontade de saber e como fruição do conhecimento por alunos e professor, ambos unidos no mesmo interesse: a aprendizagem.

Conforme Johannes relatou na pesquisa, a brincadeira pode ser usada como um recurso para enfrentar a "chatice da Gramática" e dar sentido à aprendizagem de um conteúdo que, a princípio, para os alunos, não tem sentido, como a aprendizagem do idioma Alemão, por exemplo. Por isso, para ele, o uso de jogos no ensino se inscreve na preocupação com a aprendizagem dos alunos, o que leva o professor a buscar caminhos diferentes, diferentes lugares, e não na discussão metodológica. 
A partir do que contaram os professores investigados, deduzo que a aula lúdica tampouco é apenas o encontro do ensinar com o aprender, mas um encontro do ensinar com o aprender movido pela curiosidade, pela busca do novo, pelo que surpreende e surge inesperadamente, ainda que esta aula possa ser minuciosamente planejada e pacientemente esperada.

Neusa, por exemplo, contou na pesquisa que suas ações em aula se baseiam na dialogicidade, na criação, no confronto, na autonomia, no discernimento, na ação mental e física, no compartilhamento de ideias, no levantamento de hipóteses, no comprometimento, na reflexão e no desafio, regados a muito prazer, amor e vontade de estar participando desse processo.

Essa busca da novidade reforça a semelhança da aula como festa em relação ao jogo, do ponto de vista de sua característica de imprevisibilidade e surpresa, ao menos no tocante ao professor. Entretanto, estas características também parecem ser importantes do ponto de vista do aluno: para Staccioli, em seu tempo de aluno da escola elementar, quando o professor estimulava seus alunos com um jogo qualquer - o que era muito raro - era uma alegria, pois os alunos se empenhavam, conversavam, preparavam-se, "em suma, era uma festa" (STACCIOLI, 2009, p. 22, tradução minha). Uma aula não tediosa, envolvente, desafiadora, bem-humorada, atrai os alunos para o seu núcleo, tal qual um imã - núcleo esse constituído pelo par ensino-aprendizagem. O tema do humor na sala de aula merece ser examinado mais atentamente.

\section{O humor}

Com efeito, o humor é um traço importante na opinião dos alunos para definir um bom professor (FERNANDEZ, 1998). Se admitirmos que o humor é herdeiro da capacidade de brincar, tal como Freud (1976b) ensinou, então sua identificação com a aula lúdica está plenamente legitimada.

Em uma das atividades de ludobiografia propostas na investigação, Wanda contou que ganhou dos uma agenda com os seguintes escritos: "a ludicidade das aulas, o conteúdo da disciplina fazia com que ficássemos ansiosas esperando o dia da aula"; "a professora demonstrou sempre dedicação, alegria e prazer ao lecionar"; "o domínio do conteúdo a faz falar sempre com segurança e bom humor". Além disso, o uso de materiais pouco usuais, como crônicas humorísticas, é uma outra forma do humor fazer-se presente em suas aulas.

A propósito do humor, Lulkin (2007) observa que ele e o riso são vistos ora como potentes catalisadores da crítica, ora como artifícios convenientes, tratados como um bálsamo para os acordos e conflitos dentro de uma comunidade. Repete-se, assim, aquela ambiguidade fundamental que o caracteriza, assinalada por Freud (1976b) no fato de ele tanto opor-se à realidade, quanto ajudar a enfrentá-la, e tanto proteger e conservar, quanto libertar; a mesma ambiguidade reconhecida por Larrosa (2006) na forma do riso que confronta a linguagem ordinária com seus próprios limites comunicativos e na consciência irônica em permanente tensão dialógica, rindo de si mesma. Creio até que a sua força reside justamente nessa condição paradoxal.

No fim das contas, precisamos do jogo e do humor - "paradoxos da abstração" -, como sustenta Bateson, para viver, pois sem eles a comunicação se deteria: "a vida seria então um interminável intercâmbio de mensagens estilizadas, um jogo com regras rígidas, sem o alívio da mudança ou do humor." (BATESON, 1998b, p. 220-1). Mas não somente por isso: para Kupperman, eles "aumentam a potência de pensar e de agir no mundo", o que explica porque a "lucidez é necessariamente lúdica" (2003, p. 365). Como reflete Morin, "sorrir, rir, brincar, fazer piada, acariciar e abraçar; tudo isso também é resistir": resistir a si mesmo, à crueldade do mundo, ao que há de impiedoso na política e nas relações entre os seres humanos; essa forma de resistência se chama, diz ele, esperança (20oo, p. 274).

\section{O encontro consigo mesmo}


Há, ainda, outro encontro que a aula lúdica pode promover: o encontro consigo mesmo, que, a meu ver, remete à "nostalgia do Ser" mencionada por Eliade (2010). Esse tema se relaciona ao problema ontológico do jogo, mas, agora, não no sentido do ser do próprio jogo, e sim, no "sentido do ser a partir do jogo" (FINK, 2008, p. 39, tradução minha). A aula lúdica "como se" fosse uma festa oportuniza ao jogo colocar em jogo uma de suas dimensões fundamentais, qual seja a participação na constituição do ser. Ao jogar, o ser humano se torna quem é. Isso significa que, embora o jogo não tenha essa intenção - afinal, um de seus traços característicos é, precisamente, ser autotélico, sendo sua motivação intrínseca - ele é formativo. Esta é a condição paradoxal da oposição brincar versus aprender: brincando por brincar, também se aprende, e brincar pode, sim, ensinar, desde que continue sendo brincadeira.

Para Neusa, um dos grandes legados do brincar é travar um diálogo com o nosso ser interior.

Por sua vez, para Jouet, que declarou na pesquisa ter aprendido brincando de ensinar, ser professora foi, desde sempre, um exercício permanente de entrar na alma do outro, de senti-lo e de satisfazê-lo; "é propor o que anima e faz sonhar, construindo alunos felizes", diz.

Estes depoimentos oportunizam que algo mais seja dito a respeito do encontro consigo mesmo que o jogo proporciona, e que responde, ao menos em parte, por seu fascínio: brincando entramos em contato com o que há de mais profundo e antigo em nós. Não apenas o patrimônio cultural humano, amealhado ao longo do processo civilizatório, é revolvido a cada vez que se brinca, mas todo um reservatório pessoal de sentimentos, desejos e impulsos se expressa e constitui-se brincando. Fica, então, mais evidente a procedência da associação entre a aula lúdica e a festa, na medida em que aquele desejo que a primeira tem, uma vez assimilada à segunda, de restabelecer o tempo da origem (in illo tempore), refere-se também à dimensão psíquica do ser humano. A brincadeira abre uma porta para o mundo psíquico de cada um, proporcionando uma experiência de integração por meio da qual é possível sentir-se único e o mesmo ao longo da vida, entrando em contato com o que há de mais profundo e verdadeiro dentro de si.

\section{Para além do prazer} hedonismo.

Que não se pense, contudo, que na aula lúdica vigora a tirania do prazer e o império do

Jouet, quando descreve sua prática pedagógica como sendo sempre pensada para fazer a diferença, para que as pessoas possam lembrar de fatos, construir conceitos, transpor limites sem traumas, destaca a presença do suor, junto com a atenção, de forma muito lúdica.

Aliás, duas das experiências primordiais proporcionadas pelo jogo são, precisamente, a postergação da satisfação imediata e a tolerância à frustração. A bem da verdade, o conceito de prazer figurou de forma relativamente moderada ao longo do texto, dando mais vez ao desafio, à surpresa, ao envolvimento e à busca de sentido. O prazer, na aula lúdica, como no próprio jogo, é um produto derivado: ele é resultado de uma experiência interessante e repleta de significado, que mobiliza seu sujeito integralmente e o desafia a superar-se e sentir-se capaz. É a vontade de aprender, de avançar, de compreender, de transcender-se, que traciona o prazer no jogo e, por conseguinte, na aula lúdica. A diversão, a fantasia, a expressividade emocional e a descontração, para citar apenas alguns dos elementos presentes na aula lúdica, não se opõem às lógicas transcendentes de invenção do novo e da superação de si - como pensam alguns críticos da educação centrada no lúdico, como é o caso, por exemplo, de Lipovetsky (2007): eles são capazes de integrar-se e combinar-se, desde que sob a lógica contraditorial.

Mesmo porque, um jogo não é naturalmente prazeroso ou prazeroso por si mesmo. Como esclarece Staccioli (2009), o caráter lúdico de uma situação é fortemente dependente do seu contexto: 
no caso da escola, é preciso vivê-la de maneira lúdica, pois quando um jogo adquire valor contextual irradia uma aura que o jogador percebe como prazerosa e agradável. E adverte: "nenhum jogo pode determinar um clima lúdico se a vida na aula não é lúdica", assim como "não é possível criar um clima lúdico sem usar jogos ou sem agir 'como se' jogasse” (2009, p. 22, tradução minha).

Seja como for, "uma escola do jogo não é uma escola onde se joga, mas uma escola onde o jogo e a escola são a mesma coisa" (ROVATTI; ZOLETTO, 2005, p. 9, tradução minha).

Tais ideias são convergentes com a minha convicção de que a contribuição do jogo para a educação vai muito além do ensino de conteúdos de forma lúdica, sem que os alunos sequer percebam que estão aprendendo - embora alguns professores que brincam possam eventualmente pensar assim. Acredito que a abordagem lúdica do ensino, isto é, a pedagogia lúdica, não se reduz ensinar como agir, como ser, pela imitação e pelo ensaio através do jogo, tampouco a obnubilar o ensino e os conteúdos escolares, manipulando o aluno-jogador; trata-se, isso sim, de desenvolver a imaginação, o raciocínio, a expressão e a sociabilidade (FORTUNA, 2000). Enfim, trata-se de forjar uma nova atitude em relação ao conhecimento, ao mundo, ao outro, a si mesmo e, por conseguinte, em relação à vida, com evidentes implicações para o sucesso escolar e a inclusão social. Vivenciados na brincadeira, cooperar, competir, ganhar, perder, comandar, subordinar-se, prever, antecipar, colocar-se no lugar do outro, imaginar, planejar e realizar, são aspectos fundamentais à aprendizagem em geral, presentes também na aprendizagem de conteúdos escolares. Assim, no sentido amplo, todo jogo é educativo. É por isso que a aprendizagem escolar se beneficia da brincadeira, e não porque um conteúdo específico do currículo escolar pretendeu ser ensinado por meio de um jogo (FORTUNA, 2012, 2018).

\section{CONCLUSÃO}

Mesmo sem produzir uma tipologia completa e precisa da presença da brincadeira na prática pedagógica, é possível ter uma visão ampla dos modos de brincar dos professores investigados a partir do seu relato, e, com isso, encontrar o sentido da pedagogia lúdica.

Nas falas dos professores, as relações com a ludicidade se expressam em termos de envolvimento mais amplo do e com o aluno, construção e utilização de jogos no ensino, contação de histórias e promoção da brincadeira e de lugares para brincar. Todos eles transcendem as formas canônicas de se relacionar com os alunos e com o conhecimento, de ensinar e de aprender. Ao descreverem suas práticas pedagógicas, nota-se que dão um especial lugar ao sonho, à magia e à imaginação, sendo que a maioria deles declara ter no riso, na diversão e no bom-humor a sua forma de ser professor que brinca.

No entender de Staccioli (2009), a oposição entre jogo e aprendizagem se desfaz se o contexto no qual se vive torna-se um contexto lúdico, prazeroso e sério, comprometido e alegre, rigoroso e respeitoso, ligado ao futuro e consciência do presente. A meu ver, o que ocorre com a transformação da aula e, por extensão, da escola - seja ela de que nível for - em lugar de brincar é que a brincadeira, assim, pode invadir todos os domínios da vida do professor e dos alunos. A aula como lugar de brincar é uma área intermediária, sucedânea do espaço potencial no qual se desenvolvem os fenômenos transicionais descritos por Winnicott (1975), dos quais decorrem as capacidades de pensar e fantasiar. Da mesma forma que essa área, originalmente, propicia o desenvolvimento da capacidade de brincar por meio da difusão dos fenômenos transicionais, e, a partir dela, a capacidade para a experiência cultural, a aula lúdica, ao basear-se em jogos, atividades ludiformes, atitudes lúdicas e no brincar de brincar do professor, transborda, espalhando-se por todo o campo cultural, permitindo o viver criativo e a fruição da herança cultural.

Para concluir essa reflexão relativa ao modo de ser e de dar aula do professor que brinca, possibilitada a partir dos achados da pesquisa sobre a formação lúdica docente, desejo reafirmar o princípio de que o jogo ensina, mas não naquele sentido no qual é geralmente entendido: o jogo ensina 
a educação a pensar-se na perspectiva lúdica, revolucionando suas noções de ensinar, aprender conhecimento e conteúdo escolar. Como tenho afirmado insistentemente (FORTUNA, 2000, 2005, 2012, 2013), creio que o jogo ensina a revolucionar a educação, mudar de posição, tentar de novo, ousar nova jogada, confiar no parceiro, superar limites, deixar-se levar, inebriar, não querer parar - só mais um pouquinho! Penso até que é possível que o professor aprenda mais com o jogo do que o próprio aluno, pois encontra no brincar um novo paradigma para a relação pedagógica e até para a relação com a vida. Eis o sentido de uma pedagogia lúdica.

\section{REFERÊNCIAS}

CSIKSZENTMIHALYI, M. Fluir (flow): una psicología de la felicidad. 8. ed. Barcelona: Kairós, 2000.

BATESON, G. Las categorías lógicas del aprendizaje y la comunicación (1964). In: ---. Pasos hacia una ecología de la mente: una aproximación revolucionaria a la autocompreensión del hombre. Buenos Aires: Editorial Lohlé-Lumen, 1998a. p. 309-338.

BATESON, G. Una teoría del juego y de la fantasía (1954). In: ---. Pasos hacia una ecología de la mente: una aproximación revolucionaria a la autocompreensión del hombre. Buenos Aires: Editorial Lohlé-Lumen, 1998b. p. 205-221.

BAUMAN, Z. A arte da vida. Rio de Janeiro: Jorge Zahar Editor, 2009.

BROUGÉRE, G. Brinquedos e companhia. São Paulo: Cortez Editora, 2004.

BROUGÈRE, G.; WAJSKOP, G. Entrevista: o que é brincadeira? Revista Criança do Professor de Educação Infantil, Brasília, n. 31, p. 3-9, 1999.

BUJES, M. I. Criança e brinquedo: feitos um para o outro? In: COSTA, Marisa Vorraber (org.). Estudos Culturais em Educação: mídia, arquitetura, brinquedo, biología, literatura, cinema. Porto Alegre: Editora da Universidade UFRGS, 2000. p. 205-228.

CAILLOIS, R. Os jogos e os homens: a máscara e a vertigem. (Revisão Técnica da Tradução de Tânia Ramos Fortuna). Petrópolis, RJ: Vozes, 2017.

CALLEJO, J. Fiestas sagradas: sus orígenes, ritos y significado que perviven en la tradición de los pueblos. Madrid: Editorial EDAF, 1999.

CALVINO, Í. O caminho de San Giovanni. São Paulo: Companhia das Letras, 2000.

CHAPELA, L. M. El juego en la escuela. México: Paidós, 2002.

CHARLOT, B. Da relação com o saber: elementos para uma teoria. Porto Alegre: Artmed, 2000.

CHARLOT, B. Relação com o saber, formação de professores e globalização: questões para a educação hoje. Porto Alegre: Artmed, 2005.

D’ÁVILA, C. M. Didática lúdica: saberes pedagógicos e ludicidade no contexto da educação superior. Revista Entreideias: Educação, Cultura e Sociedade, Salvador, v. 3, n. 2, p. 87-10o, jul/dez. 2014.

DEMETRIO, D. Il gioco della vita: kit autobiografico. Milano: Guerini e Associati, 1997.

DI PIETRO, A. Ludografie: reflessione i pratiche per lasciare tracce con il gioco. Molfeta: La Meridiana, 2003.

ELIADE, M. O sagrado e o profano: a essência das religiões. 3. ed. São Paulo: WMF Martins Fontes, 2010.

FERNÁNDEZ, A. Os professores devem buscar a re-significação de sua aprendizagem. Pátio Revista pedagógica, Porto Alegre, v.1, n. 4, p. 26-28, fev./abr.1998.

FINK, E. Oasi del gioco. Milano : Raffaello Cortina Editore, 2008. 
FORTUNA, T. R. Sala de aula é lugar de brincar? In: XAVIER, Maria Luiza Merino; DALLA ZEN, Maria Isabel H. (orgs.) Planejamento em destaque: análises menos convencionais. Porto Alegre: Mediação, 200o. (Cadernos de Educação Básica, 6) p. 147-164.

FORTUNA, T. R. A formação lúdica do educador. In: MOLL, Jaqueline (org.) Múltiplos alfabetismos: diálogos com a escola pública na formação de professores. Porto Alegre: Editora da UFRGS, 2005. p. 107-121.

FORTUNA, T. R.. A formação lúdica docente e a universidade: contribuições da Ludobiografia e da Hermenêutica Filosófica. Porto Alegre: UFRGS, 2011. Tese (Doutorado em Educação), Faculdade de Educação, Universidade Federal do Rio Grande do Sul, 2011. Disponível em: http://hdl.handle.net/10183/35091.

FORTUNA, T. R. Ludobiografia: uma invenção metodológica em pesquisa (auto) biográfica. In: PASSEGI, Maria da Conceição; ABRAHÃO, Maria Helena Menna Barreto (org.). Dimensões epistemológicas e metodológicas da pesquisa (auto) biográfica: Tomo II. Natal: EDUFRN; Porto Alegre: EDIPUCRS; Salvador: EDUNEB, $2012 a$. p. 165-202.

FORTUNA, T. R. Da narrativa das narrativas na pesquisa (auto) biográfica em Educação: lições para a elaboração do relato narrativo. In: ABRAHÃO, Maria Helena Menna Barreto; EGGERT, Edla; CASTRO, Amanda Motta Ângelo (org.). V CIPA: Congresso Internacional de Pesquisa (Auto) Biográfica. Porto Alegre: Programa de Pós Graduação em Educação - Faculdade de Educação - PUCRS; São Leopoldo: Casa Leiria, 2012b. p. 1-17. 1 CDROM.

FORTUNA, T. R. Professores que brincam: contribuições da ludobiografia para a compreensão da formação lúdica do professor. In: ABRAHÃO, Maria Helena Menna Barreto; FRISON, Lourdes Maria Bragnanolo (org.) Práticas docentes e práticas de (auto) formação. Porto Alegre: EDIPUCRS; Natal: EDUFRN; Salvador: EDUNEB, 2012c. p. 133-146.

FORTUNA, T. R. Por uma pedagogia do brincar. Presença Pedagógica. Belo Horizonte, ano 19, n.109, p.30-35, jan./fev. 2013.

FORTUNA, T. R. Brincar é aprender. In: GIACOMONI, Marcello Paniz; PEREIRA, Nilton Mullet. Jogos e ensino de História. Porto Alegre: Editora da UFRGS, 2018. (Série Ensino, Aprendizagem e Tecnologias). ISBN: 978-85386-0407-5. Disponível em: http://hdl.handle.net/10183/174705

FREUD, S. Escritores criativos e devaneios (1907). In: ---. Obras Psicológicas Completas de Sigmund Freud. Rio de Janeiro: Imago, 1976a. V. IX. p. 147-158.

FREUD, S. O humor (1927). In: ---. Obras Psicológicas Completas de Sigmund Freud. Rio de Janeiro: Imago, 1976b. V. XXI, p. 187-194.

GADAMER, Hans-Georg. A atualidade do belo: a arte como jogo, símbolo e festa. Rio de Janeiro: Tempo Brasileiro, 1985.

GADAMER, Hans-Georg. Verdade e método I: traços fundamentais de uma hermenêutica filosófica. 8. ed. Petrópolis: Vozes; Bragança Paulista: Editora Universitária São Francisco, 2007.

GADOTTI, M. História das ideias pedagógicas. São Paulo: Editora Ática, 2005.

GREEN, A. Um psicanalista engajado: conversas com Manuel Macias. São Paulo: Casa do Psicólogo, 1999.

HUIZINGA, J. Homo ludens. 4. ed. São Paulo: Perspectiva, 1993.

KUPERMANN, D. Ousar rir: humor, criação e psicanálise. Rio de Janeiro: Civilização Brasileira, 2003.

LARROSA, J. Pedagogia profana: danças, piruetas e mascaradas. 4. ed. Belo Horizonte: Autêntica, 2006.

LIPOVETSKY, G. A felicidade paradoxal: ensaio sobre a sociedade de hiperconsumo. São Paulo: Companhia das Letras, 2007. 
LULKIN, S. A.. O riso nas brechas do siso. Porto Alegre: UFRGS, 2007. Tese (Doutorado em Educação) Programa de Pós-Graduação em Educação, Faculdade de Educação, Universidade Federal do Rio Grande do Sul, 2007.

MAFFESOLI, M. A sombra de Dioniso: contribuição a uma sociologia da orgia. 2. ed. São Paulo: Zouk, 2005.

MAFFESOLI, M. Elogio da razão sensível. 4. ed. Petrópolis (RJ): Vozes, 2008.

MARQUES, T. B. I. Do egocentrismo à descentração: a docência no ensino superior. Porto Alegre: UFRGS, 2004. Tese (Doutorado) - Programa de Pós-Graduação em Educação, Faculdade de Educação, Universidade Federal do Rio Grande do Sul, 2005.

MORIN, E. Meus demônios. Rio de Janeiro: Bertrand, 2000.

OLIVEIRA, V. B.; BORJA SOLÉ, M.; FORTUNA, T. R. Brincar com o outro: caminho de saúde e bem-estar. Petrópolis, RJ: Vozes, 2010. (Coleção Brinquedo, Educação e Saúde).

ORBETTI, D.; SAFINA, R.; STACCIOLI, G. Raccontarsi a scuola: tecniche di narrazione autobiografica. Roma: Carocci Faber, 2005.

OUTEIRAL, J. O.; MOURA, L. Paixão e criatividade: estudos psicanalíticos sobre Frida Kahlo, Camille Claudel, Coco Chanel. 2. ed. Rio de Janeiro: Revinter, 2002.

PASCAL, B. Pensamentos. 2. ed. São Paulo: Martins Fontes, 2005.

ROVATTI, P. A.; ZOLETTO, D. La scuola dei giochi. Milano: Tascabili Bompiani, 2005.

SARLÉ, P. M. Ensenar el juego y jugar la enseñanza. Buenos Aires: Paidós, 2006.

STACCIOLI, G. Il gioco nel gioco del giocatore. In: DI PIETRO, Antonio. Ludografie: reflessione i pratiche per lasciare tracce con il gioco. Molfeta: La Meridiana, 2003. p. 47-92.

STACCIOLI, G. La ludobiografia: un modo per raccontare e raccontarsi giocando insieme. In: ORBETTI, Daniela; SAFINA, Rossella; STACCIOLI, Gianfranco. Raccontarsi a scuola: tecniche di narrazione autobiografica. Roma: Carocci Faber, 2005. p. 88-136.

STACCIOLI, G. I giochi che fanno crescere: analisi e proposte di giochi di pedine per uma didattica ludica. Pisa: Edizioni ETS, 2009.

STACCIOLI, G. Ludobiografia: raccontare e raccontarsi con il gioco. Roma: Carocci Editore, 2010.

SUTTON-SMITH, B. A ambiguidade da brincadeira. (Revisão Técnica da Tradução de Tânia Ramos Fortuna). Petrópolis, RJ: Vozes, 2017.

TERR, L. El juego: por qué los adultos necesitan jugar. Barcelona: Paidós, 2000.

VISALBERGHI, A. Problemi della ricerca pedagogica. Firenze: La Nuova Itália Editrice, 1965.

WINNICOTT, D. W. O brincar e a realidade. Rio de Janeiro: Imago, 1975.

Tânia Ramos Fortuna: Doutora em Educação. Professora de Psicologia da Educação da Faculdade de Educação da Universidade Federal do Rio Grande do Sul (UFRGS). Coordenadora Geral do Programa de Extensão Universitária “Quem quer brincar?" (www.ufrgs.br/quemquerbrincar).

E-mail: tania.fortuna@terra.com.br 